\title{
Prolactin-Producing Pituitary Adenoma With Abundant Spherical Amyloid Deposition Masquerading as Extensive Calcification \\ -Case Report-
}

\author{
Yuriz BAKHTIAR, Kazunori ARITA, Hirofumi HiRANO, Mika HABU, \\ Shingo FUjIO, Shinichi KITAJIMA*, and Akihide TANIMOTO* \\ Department of Neurosurgery; and *Department of Tumor Pathology, Field of Oncology; \\ Graduate School of Medical and Dental Sciences, Kagoshima University, Kagoshima
}

\begin{abstract}
A 53-year-old male presented with a case of prolactin-producing pituitary adenoma with abundant spherical amyloid depositions masquerading as extensive calcification and manifesting as visual disturbance. Computed tomography revealed a large high density mass suggesting calcified tumor in the intra- and supra-sellar regions. Magnetic resonance imaging revealed a heterogeneously enhanced large pituitary tumor reaching lateral ventricle. Blood prolactin level was elevated to $5971 \mathrm{ng} / \mathrm{ml}$. Cabergoline treatment for 3 months provided considerable shrinkage of the tumor but failed to improve the visual symptoms. Transcranial surgery revealed that the tumor was fibrous and included abundant grayish translucent spherical granules with diameter of 0.5-1.5 mm. Immunohistochemically, the tumor was strongly positive for prolactin. Congo red stain and polarized light showed that these spherical bodies were amyloid depositions. No calcification was noted.
\end{abstract}

Key words: pituitary nucleoplasm, prolactinoma, spherical amyloid, pseudocalcification

\section{Introduction}

Amyloid is known to accumulate in normal and neoplastic endocrine tissue secreting peptide hormones. Amyloid

Received February 2, 2010; Accepted April 8, 2010 deposit in a pituitary adenoma was first described in 1972.1) Pituitary adenoma is a peptide hormone-secreting tumor known to show accumulation of amyloids in $71 \%$ of cases, as the more common stellate/perivascular and rare spherical types. The stellate/perivascular type occurs in all endocrine types of pituitary adenoma and is characterized 
by stellate, intercellular, and perivascular deposits, whereas the spherical type, a rare entity almost exclusively encountered in prolactin (PRL)-producing adenomas, occurs as many spheroid accumulations with variable diameters $(40-1500 \mu \mathrm{m}) .^{14,20)}$

We describe a case of a large prolactinoma with abundant spherical amyloid depositions appearing as high density spots on computed tomography (CT) mimicking extensive calcification.

\section{Case Report}

A 53-year-old man was referred to our department with complaints of headache and blurred vision. Perimetry revealed left homonymous hemianopia. CT revealed an intraand supra-sellar tumor including abundant high density spots resembling calcifications (Fig. 1). Magnetic resonance (MR) imaging revealed a large pituitary adenoma $45 \mathrm{~mm}$ in height extending up to the lateral ventricle with a cystic component at its top (Fig. 2). MR imaging showed the tumor as mixed iso-hypointense to the white matter on $\mathrm{T}_{1}$-weighted imaging (Fig. 2A) and mixed hypo-isointense on $\mathrm{T}_{2}$-weighted imaging (Fig. 2B), with
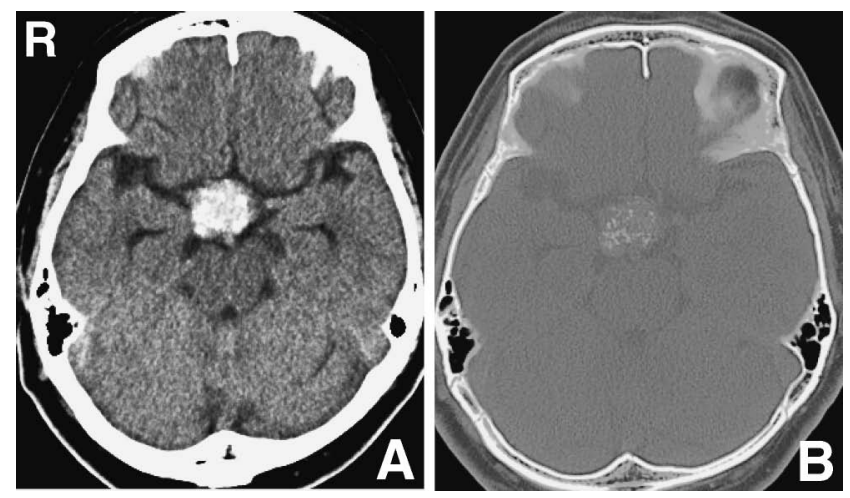

Fig. 1 A: Computed tomography (CT) scan revealing an intraand supra-sellar high density lesion appearing to be extensively calcified. B: Bone density CT scan showing that the tumor included numerous small high density spots.
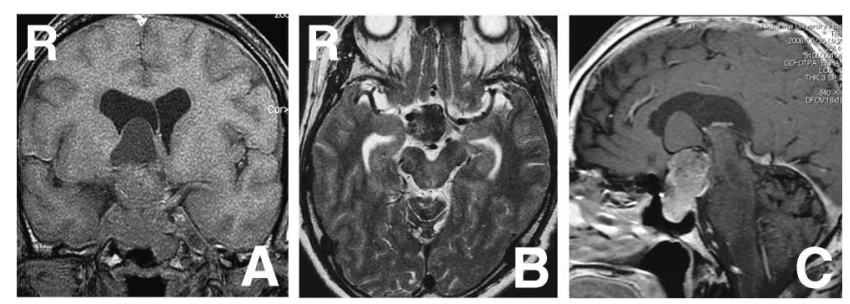

Fig. 2 Magnetic resonance images revealing a large $45 \times 25$ $\times 25 \mathrm{~mm}$ pituitary adenoma containing a cyst reaching lateral ventricle, appearing as mixed iso-hypointensity to the white matter on the $T_{1}$-weighted image (A) and mixed hypo-isointensity on the $T_{2}$-weighted image (B), with heterogeneous enhancement (C). Abundant hypointensity spots are also shown by meticulous observation (A, B). heterogeneous enhancement (Fig. 2C). $\mathrm{T}_{1^{-}}$and $\mathrm{T}_{2}$-weighted MR imaging also displayed abundant hypointense spots.

Hormonal analysis revealed extreme elevation of blood PRL concentration to $5971 \mathrm{ng} / \mathrm{ml}$. Cabergoline was given with an initial dose of $0.5 \mathrm{mg} / \mathrm{week}$ and increased up to 2 $\mathrm{mg} /$ week. MR imaging after 3 months of cabergoline treatment showed remarkable reduction of tumor size (Fig. 3). The PRL level had also decreased to $92.7 \mathrm{ng} / \mathrm{ml}$. However, his visual function did not improve. Tumor removal and decompression of the optic nerve/chiasma was attempted through the interhemispheric approach. However, only partial removal was possible because of the fibrous texture of the tumor. Abundant translucent whitish spherical accumulations, around $0.5-1.5 \mathrm{~mm}$ in diameter (Fig. 4A),
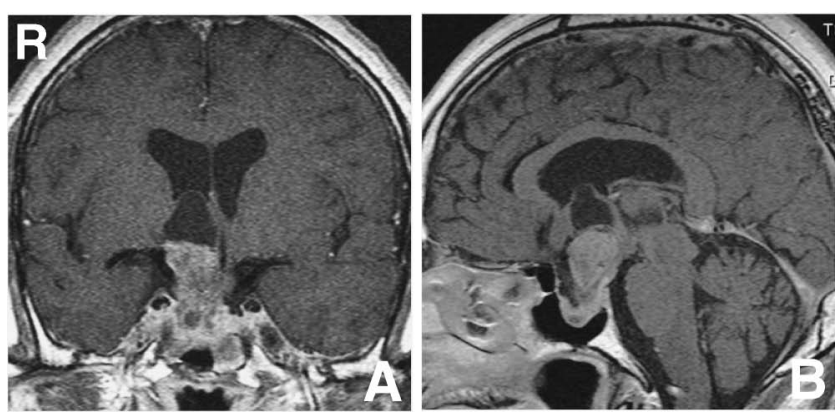

Fig. 3 Coronal (A) and sagittal (B) magnetic resonance images after 3 months of cabergoline treatment showing remarkable reduction of tumor size.
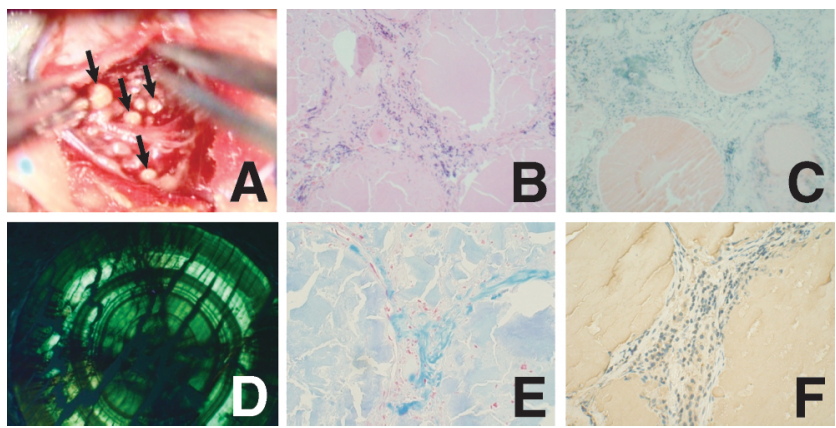

Fig. 4 A: Surgical microscope image showing the tumor containing innumerable tiny roe-like grayish granules, 0.5-1.5 mm in diameter (arrows). B-F: Photomicrographs showing the chromophobic tumor cells with nuclear pleomorphism and abundant amorphous and round eosinophilic material, surrounded by loose connective tissue infiltrated by lymphocytes and macrophages (B: hematoxylin and eosin stain, original magnification $\times 100$ ), the round eosinophilic materials stained positively and showing birefringence under polarized light with Congo red (C: Congo red stain, original magnification $x$ 100; D: polarized light, original magnification $\times 200$ ), with reticulin fibers surrounding the hypotrophic adenoma cells (E: Malory-Azan stain, original magnification $\times 200$ ), and the adenoma cells and spherical bodies strongly immunoreactive for prolactin (F: original magnification $\times 200$ ). 
were found in the tumor. The tumor had penetrated the right optic tract and the bilateral optic nerves were displaced to the sellar floor. The visual field defect did not change after the surgery. Postoperative cabergoline treatment continued to provide good control of the tumor size and PRL levels.

Histological examination revealed that the tumor consisted of small groups of hypotrophic adenoma cells, generally chromophobic with nuclear pleomorphism, scattered against fibrous hyaline stroma, and abundant round and amorphous eosinophilic material (200-1500 $\mu \mathrm{m}$ ) (Fig. 4B). The round bodies were stained positively with Congo red and showed birefringence under polarized light, indicative of amyloid (Fig. 4C, D). The amyloids were surrounded by loose connective tissue and fibroblasts infiltrated by lymphocytes and macrophages. Malory-Azan staining showed increased reticulin fibers surrounding the hypotrophic adenoma cells (Fig. 4E). Calcification was not observed by either hematoxylin and eosin or von Kossa staining. Immunohistochemical staining showed that the adenoma cells were strongly positive for PRL (Fig. 4F). The spherical bodies were also positive for PRL (Fig. 4F). The MIB-1 index for this tumor was around $5 \%$.

\section{Discussion}

In our case, the abundant spherical bodies observed during surgery were proven to be accumulation of amyloid. The size and distribution of the amyloid bodies roughly coincided with the high density spots on preoperative CT, which were interpreted as calcifications. Hematoxylin and eosin or von Kossa stain did not show any type of calcification. Therefore, we determined that these granular high density spots on CT were amyloid bodies. Bone image CT indicated that the density of the granular materials was much lower than that of bone density.

Amyloid deposits are caused by twisted $\beta$-plated sheet fibril accumulation forming micellar structures of $\beta$ protein.7) The pathogenesis of amyloid deposition in prolactinoma is still unknown. Amyloid fibril proteins are known to be fragments of larger protein precursors. ${ }^{2,4,23)}$ Synthetic peptides of PRL can form amyloid fibrils in vitro. ${ }^{23)}$ Electron microscopy identified non-membranelimited fibrils in neoplastic cells in a prolactinoma with spherical amyloid bodies, suggesting that these intracellular fibrils are the intracellular source of amyloid. ${ }^{12)}$ Spherical amyloid deposits in prolactinoma are generally positive for PRL in immunohistochemical staining as in our case. ${ }^{3-5,11,12,17,19,24)}$ Further, amyloid deposition in pituitary adenoma has been associated with local conditions suggesting that the amyloid fibrils are produced by adenoma during degeneration. ${ }^{3,6,12,17,18,24)}$ Therefore, we suggest that deposition of amyloid may be related with the PRL synthesis process and may be enhanced by naturally developed degenerative change in prolactinoma, as seen in our case. Another possibility is that mesenchymal histiocytes produce the amyloid by unknown processes and accumulation is enhanced by dopamine agonist therapy. ${ }^{5,12,20,24)} \mathrm{In}$ our case, the 3-month period of preoperative administra- tion of cabergoline, a long-acting dopamine agonist, was relatively short. Moreover, CT demonstrated high density spots before the drug therapy. Therefore, the amyloid deposition did not seem to be related to cabergoline treatment in our case.

Materials with high protein concentration appear as hyperdense on CT. ${ }^{21,22)}$ Some intracranial cystic tumors including Rathke's cleft cyst and epidermoid cyst appear as hyperdense on CT due to high protein levels. ${ }^{16,21)}$ Spherical amyloid in pituitary adenoma contained an abundance of 4-kDa peptides. However, two previous reports on CT findings of amyloid deposited in pituitary adenoma showed decreased attenuation of the tumor. ${ }^{12,13)}$ This discordance may be attributed to differences in the size and population of spherical amyloid bodies. Our case consisted of adenoma tissue containing abundant large, 0.5-1.5 $\mathrm{mm}$ in diameter, spherical amyloid bodies. Characteristic MR imaging findings of amyloid deposits include low intensity on $\mathrm{T}_{1}$-weighted images and even lower intensity on $\mathrm{T}_{2}$-weighted images relative to the gray matter. ${ }^{17)}$ These findings are concordant with our case.

Twenty-five cases of histologically proven spherical amyloid body in pituitary adenoma have been reported. ${ }^{3-6,8-15,17-20,24)}$ All tumors except one growth hormone (GH)-producing adenoma ${ }^{18)}$ were prolactinoma. The 9 male and 16 female patients were aged from 21 to 71 years. The tumor size was described in 9 cases, ranging 10-45 mm (mean \pm standard deviation [SD], $17 \pm 10.03$ ). Patients with prolactinoma showed blood PRL levels ranged from 2.4 to $33000 \mathrm{ng} / \mathrm{ml}$ (mean \pm SD, $3592.8 \pm$ 7628.8). Symptoms of hyperprolactinemia such as menstrual disturbance, libido, and fertility problems were recorded in most patients with prolactinoma, and 4 patients suffered from headache and blurred vision. The deposits measured between 40 and $1500 \mu \mathrm{m}$ and were usually immunopositive for PRL, and were positive for both GH and PRL in two tumors. Neither PRL nor GH was detected in the deposits in three tumors.

The primary treatment for prolactinoma is medical therapy with dopamine agonist, which generally dramatically reduces PRL level and tumor size with acceptable adverse effects. In our case, short-term cabergoline administration provided remarkable decrease of PRL level and tumor size. However, the visual field defect did not improve, although the patient reported transient hazy vision during the treatment. Surgical exploration revealed that the tumor had penetrated the right optic tract and both optic nerves were displaced to the sellar floor. Reduction of tumor volume did not improve his visual function, but even transient deterioration might have occurred due to the sinking of the optic chiasm and nerves associated with descent of the tumor. Fortunately, reinstitution of cabergoline treatment has induced steady decrease of the PRL level and tumor size without further deterioration of vision.

The present case of large prolactinoma was packed with innumerable spherical amyloid deposits, which appeared as high density granules on CT and mimicked extensive calcification. The amyloid deposition did not seem to be related to the preoperative cabergoline treatment. 


\section{Acknowledgment}

This work was aided by Research Grants, Research on Hypothalamo-Pituitary Dysfunction from the Ministry of Health, Labour and Welfare-Japan (to K.A.), and Kiban Research Grant C, 2009 (to K.A.) from the Ministry of Education, Culture, Sports, Science and Technology-Japan.

\section{References}

1) Barr R, Lampert P: Intrasellar amyloid tumor. Acta Neuropathol 21: 83-86, 1972

2) Benvenga $S$, Cannavò $S$, Trimarchi $F$ : Prolactin is an amyloid-related protein. J Endocrinol Invest 27: 209-210, 2004

3) Bononi PL, Martinez AJ, Nelson PB, Amico JA: Amyloid deposits in prolactin-producing pituitary adenoma. J Endocrinol Invest 16: 339-343, 1993

4) Canda T, Sengiz S, Canda MS, Acar UD, Erbayraktar S, Yilmaz S: Histochemical and immunohistochemical features of case showing association of meningioma and prolactinoma containing amyloid. Brain Tumor Pathol 19: 1-3, 2002

5) Delafontaine P, Ochsner F, Pizzolato GP: Pituitary adenoma with amyloid deposits and hyperprolactinemia. Acta Neuropathol 57: 81-84, 1982

6) Filippi E, Cornaggia M, Riva C, Turolla E: [Spheroidal deposits of amyloid in prolactin-secreting pituitary adenomas]. Pathologica 84: 205-214, 1992 (Italian)

7) Glenner GG, Eanes ED, Bladen HA, Linke RP, Termine JD: Beta-pleated sheet fibrils. A comparison of native amyloid with synthetic protein fibrils. J Histochem Cytochem 22: 1141-1158, 1974

8) Gul S, Bahadir B, Dusak A, Kalayci M, Edabili N, Acikgoz B: Spherical amyloid deposition in a prolactin-producing pituitary adenoma. Neuropathology 29: 81-84, 2009

9) Hinton DR, Polk RK, Linse KD, Weiss MH, Kovacs K, Garner JA: Characterization of spherical amyloid protein from prolactin-producing pituitary adenoma. Acta Neuropathol 93: 43-49, 1997

10) Jimenez L, Rivera ML, Ferra S, Colon LE, Carro E: Prolactinoma with extensive amyloid deposits: a case report. $P$ R Health Sci J 27: 343-345, 2008

11) Kim SH, Kim SH, Lee SK, Kim TS: Squash smear findings of spherical amyloid in pituitary prolactinoma. A case report. Acta Cytol 48: 447-450, 2004

12) Kubota T, Kuroda E, Yamashima T, Tachibana O, Kabuto M,
Yamamoto S: Amyloid formation in prolactinoma. Arch Pathol Lab Med 110: 72-75, 1986

13) Kuratsu J, Matsukado Y, Miura M: Prolactinoma of pituitary with associated amyloid-like substances. J Neurosurg 59: 1067-1070, 1983

14) Landolt AM, Heitz PU: Differentiation of two types of amyloid occurring in pituitary adenomas. Pathol Res Pract 183: 552-554, 1988

15) Landolt AM, Kleihues P, Heitz PU: Amyloid deposits in pituitary adenomas. Arch Pathol Lab Med 111: 453-458, 1987

16) Li F, Zhu S, Liu Y, Chen G, Chi L, Qu F: Hyperdense intracranial epidermoid cysts: a study of 15 cases. Acta Neurochir (Wien) 149: 31-39, 2007

17) Martin SW, Lefton DR, Pinto RS, Rosenblum M, Elowitz E: MR imaging characteristic of amyloid deposits in pituitary adenoma. AJNR Am J Neuroradiol 23: 368-370, 2002

18) Mori H, Mori S, Saitoh Y, Moriwaki K, Iida S, Matsumoto K: Growth hormone-producing pituitary adenoma with crystallike amyloid immunohistochemically positive for growth hormone. Cancer 55: 96-102, 1985

19) Paetau A, Partanen S, Mustajoki P, Valtonen S, Pelkonen R, Wahlstrom T: Prolactinoma of the pituitary containing amyloid. Acta Endocrinol (Copenh) 109: 176-180, 1985

20) Saitoh $Y$, Mori H, Matsumoto K, Ushio Y, Hayakawa T, Mori A, Arita N, Mogami H: Accumulation of amyloid in pituitary adenomas. Acta Neuropathol 68: 87-92, 1985

21) Silverman SG, Mortele KJ, Tuncali K, Finzaki M, Cibas ES: Hyperattenuating renal masses: etiologies, pathogenesis, and imaging evaluation. Radiographics 27: 1131-1143, 2007

22) Timmer FA, Sluzewski M, Treskes M, Van Rooij WJJ, Teepen JLJM, Wijnalda D: Chemical analysis of an epidermoid cyst with unusual CT and MR characteristic. AJNR Am J Neuroradiol 19: 1111-1112, 1998

23) Westermark P, Eriksson L, Engstrom U, Enestrom S, Sletten $\mathrm{K}$ : Prolactin-derived amyloid in the aging pituitary gland. Am J Pathol 150: 67-73, 1997

24) Wiesli P, Brandle M, Brandner S, Kolias SS, Bernays RL: Extensive spherical amyloid deposition presenting as a pituitary tumor. J Endocrinol Invest 26: 552-555, 2003

Address reprint requests to: Kazunori Arita, M.D., Department of Neurosurgery, Graduate School of Medical and Dental Sciences, Kagoshima University, 8-35-1 Sakuragaoka, Kagoshima 890-8520, Japan. e-mail:karita@m2.kufm.kagoshima-u.ac.jp 